\title{
Oxyhydride Nature of Rare-Earth-Based Photochromic Thin Films
}

\author{
Steffen Cornelius, ${ }^{*}{ }^{\dagger}$ Giorgio Colombi, ${ }^{\dagger}$ Gahimeh Nafezarefi, ${ }^{\dagger}$ Herman Schreuders, ${ }^{\dagger}$ René Heller, ${ }^{\dagger}$ \\ Frans Munnik, and Bernard Dam ${ }^{\dagger}$
${ }^{\dagger}$ Materials for Energy Conversion and Storage, Department of Chemical Engineering, Delft University of Technology, Van der Maasweg 9, NL-2629HZ Delft, The Netherlands
${ }^{\ddagger}$ Helmholtz-Zentrum Dresden-Rossendorf, Institute of Ion Beam Physics and Materials Research, Bautzner Landstrasse 400, D-01328 Dresden, Germany

Supporting Information

ABSTRACT: Thin films of rare-earth (RE)-oxygen-hydrogen compounds prepared by reactive magnetron sputtering show a unique color-neutral photochromic effect at ambient conditions. While their optical properties have been studied extensively, the understanding of the relationship between photochromism, chemical composition, and structure is limited. Here we establish a ternary $\mathrm{RE}-\mathrm{O}-\mathrm{H}$ composition-phase diagram based on chemical composition analysis by a combination of Rutherford backscattering and elastic recoil detection. The photochromic films are identified as oxyhydrides with a wide composition range described by the formula $\mathrm{REO}_{x} \mathrm{H}_{3-2 x}$ where $0.5 \leq x \leq 1.5$. We propose an anion-disordered structure model based on the face-centered cubic unit cell where the $\mathrm{O}^{2-}$ and $\mathrm{H}^{-}$anions occupy tetrahedral and octahedral interstices. The optical band gap varies continuously with the anion ratio, demonstrating the potential of band gap tuning for reversible optical switching applications.

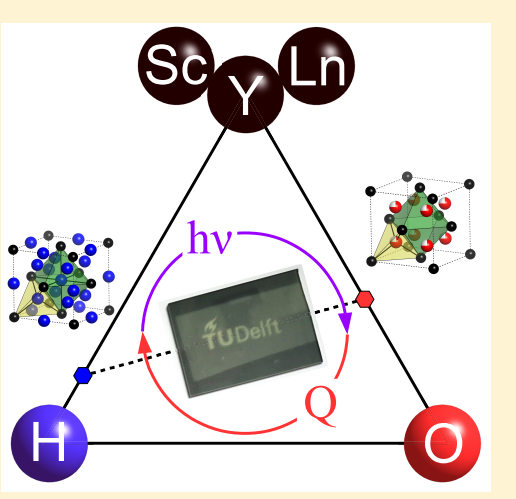

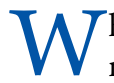
hile the structure-property relationships of single-anion materials, such as metal oxides, are to a large extent determined by variations in the cation chemistry, multianion compounds offer another dimension of control of material properties. This is due to the wide range of different anion characteristics, including electronegativity, polarizability, and ionic radius. ${ }^{1}$ Perhaps the least studied group of multianion compounds are oxyhydrides where both oxide $\left(\mathrm{O}^{2-}\right)$ and hydride $\left(\mathrm{H}^{-}\right)$ions are present. Since the successful synthesis of the transition metal (TM) oxyhydride $\mathrm{LaSrCoO}_{3} \mathrm{H}_{0.7}$ by Hayward et al., ${ }^{2}$ this material class has been extended to TM = Sc, Ti, V, Cr, Mn, Co based on the perovskite and the layered Ruddlesden-Popper crystal structure types. ${ }^{3}$ A recent report on hydride ion $\left(\mathrm{H}^{-}\right)$conductivity in $\mathrm{La}_{2-x-y} \mathrm{Sr}_{x+y} \mathrm{Li}_{1-x} \mathrm{HO}_{3-y}$ makes oxyhydrides promising materials for energy storage and conversion applications. ${ }^{4}$ Two synthesis routes for TM oxyhydrides have been established to date. Topochemical synthesis exploits the $\mathrm{O}^{2-} / \mathrm{H}^{-}$anion exchange between the parent oxide and a hydride (mostly $\mathrm{CaH}_{2}$ ) at moderate temperatures of $300-600{ }^{\circ} \mathrm{C} .^{3}$ Alternatively, some TM oxyhydrides have been prepared by highpressure (few GPa) direct synthesis from parent oxide and hydride powder mixtures at $1000-1300{ }^{\circ} \mathrm{C} .^{3}$ These methods have also been employed to synthesize powders of lanthanide ( $\mathrm{Ln}$ ) oxyhydrides $\mathrm{LnOH}$ with $\mathrm{Ln}=\mathrm{La},{ }^{5} \mathrm{Nd},{ }^{6} \mathrm{Sm},{ }^{7,8}$ $\mathrm{Gd}-\mathrm{Er}^{7-9}$, the second established class of oxyhydride materials. The stoichiometric $\mathrm{LnOH}$ are reported to crystallize either in the anion-disordered face-centered cubic (fcc) fluorite type structure $(F m \overline{3} m)^{7-9}$ or in an anion-ordered superstructure with tetragonal $(P 4 / \mathrm{nmm})$ symmetry. ${ }^{5,6}$ To date, the electronic properties of the lanthanide oxyhydrides remain largely unexplored. A recent study by Ueda et al. suggests that $\mathrm{Tb}^{3+}$-doped $\mathrm{GdOH}$ is a promising candidate for phosphor applications. $^{9}$

A remarkable photochromic effect at ambient conditions was discovered in reactive magnetron sputtered (MS) $\mathrm{YO}_{x} \mathrm{H}_{y}$ thin films. ${ }^{10}$ Initially, these semiconducting materials (band gap $E_{g} \approx 2.6 \mathrm{eV}$ ) were referred to as oxygen-containing yttrium hydride. $^{10,11}$ It was speculated that their properties can be explained in analogy to the transparent $\gamma-\mathrm{YH}_{3}$ phase stabilized in the fcc structure by incorporation of oxygen into the lattice. ${ }^{11}$ A later study on sputtered $\mathrm{YO}_{x} \mathrm{H}_{y}$ composition gradient thin films, which covers the transition from opaque to transparent state, reports atomic ratios of up to $\mathrm{H} / \mathrm{Y} \approx 3$ as measured by heavy-ion elastic recoil detection (ERD) and nuclear reaction analysis (NRA). ${ }^{12}$ However, this result seems rather questionable considering the low $\mathrm{H}_{2}$ partial pressures during reactive MS deposition. Follow-up studies by Montero et al. ${ }^{13}$ and Nafezarefi et al. ${ }^{14}$ clarified that the transparent $\mathrm{YO}_{x} \mathrm{H}_{y}$ materials are in fact formed by air oxidation of asdeposited absorbing metallic $\beta-\mathrm{YH}_{2}$ films. Further, we reported that $\mathrm{LnO}_{x} \mathrm{H}_{y}$ thin films with $\mathrm{Ln}=\mathrm{Gd}$, Dy, Er exhibit the same photochromic effect and fcc crystal structure as $\mathrm{YO}_{x} \mathrm{H}_{y}{ }^{14} \mathrm{On}$ the basis of these findings and our preliminary chemical composition analysis experiments, we then adopted the term rare-earth (RE) oxyhydrides for this group of photochromic

Received: January 11, 2019

Accepted: February 20, 2019

Published: March 7, 2019 
materials. However, systematic experimental evidence for the presence of $\mathrm{H}^{-}$ions in these $\mathrm{REO}_{x} \mathrm{H}_{y}$ is scarce. Although a recent study by Moldarev et al. supports the concept of $\mathrm{H}^{-}$in their photochromic $\mathrm{YO}_{x} \mathrm{H}_{y}$ films, they also had to assume multiple cation charge states and/or the presence of $\mathrm{OH}^{-}$ complex ions in order to obtain charge balance. ${ }^{15}$ Moreover, the relationship of the photochromic $\mathrm{REO}_{x} \mathrm{H}_{y}$ thin films to the established group of stoichiometric $\mathrm{LnOH}$ bulk materials in terms of chemical composition and crystal structure remained unclear.

Here, we address these open questions by a combination of chemical composition analysis via ion beam methods, charge neutrality arguments, and optical characterization. We find that the photochromic $\mathrm{REO}_{x} \mathrm{H}_{y}$ films are indeed oxyhydridesclearly distinct from hydroxides-having a wide composition range along the $\mathrm{MH}_{3}-\mathrm{M}_{2} \mathrm{O}_{3}$ axis. This allows us to explain their properties in the framework of $\mathrm{O}^{2-} / \mathrm{H}^{-}$anion-disorder, linking the known (anion-ordered) structures of $\mathrm{REH}_{3}$ trihydrides, $\mathrm{LnOH}$, and the $\mathrm{RE}_{2} \mathrm{O}_{3}$ sesquioxides.

Recently, we reported that metallic $\beta-\mathrm{MH}_{1.9+\delta}$ dihydride thin films with $\mathrm{M}=\mathrm{Y}, \mathrm{Er}$, Dy, Gd can be prepared by direct current (DC) reactive MS of metal targets in an $\mathrm{Ar} / \mathrm{H}_{2}$ atmosphere. ${ }^{14}$ Above a certain material-dependent critical deposition pressure $\left(p^{*}\right)$, the films air-oxidize at room temperature (RT) to form stable semiconducting transparent photochromic $\mathrm{MO}_{x} \mathrm{H}_{y}$. In order to obtain samples with a wide range of chemical compositions, we have extended our standard synthesis procedure as follows: (i) Sc is sputtered as the RE element with the smallest ionic radius. (ii) A variable amount of $\mathrm{O}_{2}$ is added to the $\mathrm{Ar} / \mathrm{H}_{2} / \mathrm{O}_{2}$ process gas ( $5 \mathrm{~N}$ purity) resulting in a mixture containing (12.5-11.9) \% of $\mathrm{H}_{2}$ and $(0-4.7) \%$ of $\mathrm{O}_{2}$. (iii) Pulsed DC plasma excitation $(50 \mathrm{kHz}, 90 \%$ duty cycle) is used to avoid arcing. (iv) Al capping layers $(20 \mathrm{~nm}$ ) were sputtered onto selected samples directly or after timed air exposure to prevent further oxidation. All samples were grown on unheated UV-grade fused silica $\left(\mathrm{f}-\mathrm{SiO}_{2}\right)$ and polished glassy carbon substrates (HTW Germany). Structural and optical properties were investigated by a combination of X-ray diffraction (XRD, Bruker D8 Discover) and photospectrometry (PerkinElmer Lambda 900). A custom-built optical-fiberbased in situ spectrometer (range: 230-1150 nm) with attached $385 \mathrm{~nm}$ LED light source and a time resolution of $\sim 1 \mathrm{~s}$ was employed to test the photochromic properties.

The $\mathrm{MO}_{x} \mathrm{H}_{y}$ chemical composition is determined by a combination of Rutherford backscattering spectrometry (RBS) and ERD analysis at the $2 \mathrm{MV}$ Van-de-Graaff accelerator at Helmholtz-Zentrum Dresden-Rossendorf (Dresden, Germany). RBS (ERD) measurements were performed with a $1.7 \mathrm{MeV}{ }^{4} \mathrm{He}^{+}$beam at $0^{\circ}\left(70^{\circ}\right)$ incidence and $160^{\circ}\left(30^{\circ}\right)$ scattering angle using semiconductor detectors with a solid angle of $3.3 \mathrm{msr}(5.6 \mathrm{msr})$ and an energy resolution of $\sim 15 \mathrm{keV}$. The ERD detector was covered by a $6.6 \mu \mathrm{m} \mathrm{Al}$ stopper foil to discriminate recoiled $\mathrm{H}$ from forward scattered He. A special set of Sc, Y, and Gd dihydride reference samples was prepared by hydrogenating Pd-capped $(20 \mathrm{~nm})$ metal layers $(150 \mathrm{~nm})$ in a pressure cell at 1 bar of $\mathrm{H}_{2}$ at RT. Employing the hydrogenography method, ${ }^{16}$ the change in optical transmittance is used to verify that all films were initially loaded to $\mathrm{H} / \mathrm{M}$ ratios above the dihydride to trihydride phase transition, followed by unloading to dihydride in air after opening the pressure cell. Because of the tensile strain induced by hydrogen desorption, ${ }^{17}$ we expect that these dehydrogenated layers have a $\mathrm{H} / \mathrm{M}$ ratio corresponding to the lower end of the $\beta-\mathrm{MH}_{x}$ existence range, i.e., $\mathrm{ScH}_{1.68}{ }^{18}$ $\mathrm{YH}_{1.90},{ }^{17}$ and $\mathrm{GdH}_{1.80}$ (see Figures $\mathrm{S} 1-\mathrm{S} 3$ for XRD characterization). These dihydride samples turned out to be crucial to accurately calibrate the solid angle of the ERD detector. For each sample, the RBS and ERD spectra were fitted selfconsistently using the SIMNRA ${ }^{19}$ program and the SRIM2013 stopping power database. ${ }^{20}$

The result of this analysis is illustrated in Figure 1, showing the experimental ion beam spectra and corresponding

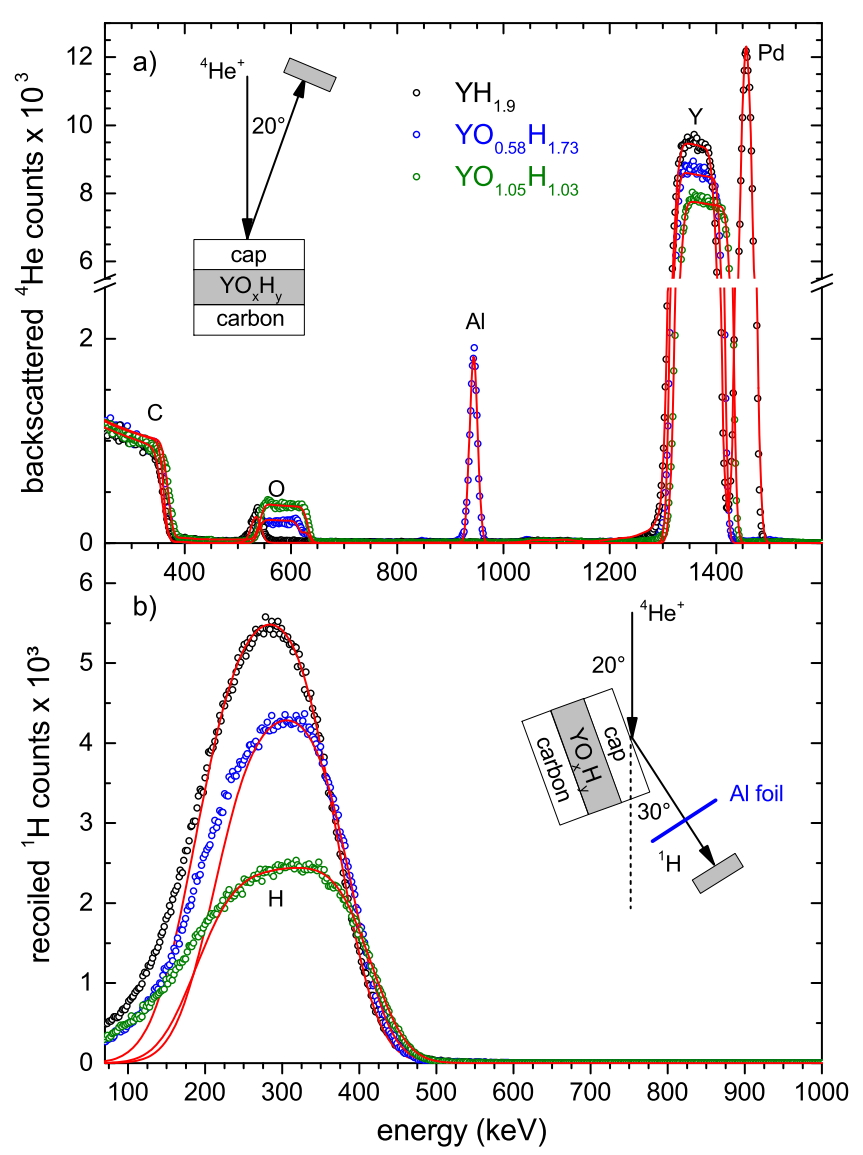

Figure 1. Comparison of (a) RBS and (b) ERD experimental spectra (open circles) and corresponding SIMNRA simulations (red lines) obtained by fitting of each combined data set. A series of samples (150 nm thickness) with increasing oxygen content is shown: Pdcapped Y dihydride (black), Al-capped (blue), and uncapped $\mathrm{Y}$ oxyhydride (green). The broadening of the low-energy edge in the ERD spectrum is caused by thickness variations of the Al stopper foil.

simulations of a set of $\mathrm{YO}_{x} \mathrm{H}_{y}$ films with different $\mathrm{O} / \mathrm{H}$ ratios. The areal densities (atoms $/ \mathrm{cm}^{2}$ ) of $\mathrm{Y}$ and $\mathrm{O}$ are obtained from RBS data, taking into account the $\mathrm{Al}$ or Pd capping layers. The overall fit accuracy benefits from the nearly background-free oxygen signal with good counting statistics, which is achieved by the use of carbon instead of $\mathrm{f}-\mathrm{SiO}_{2}$ substrates. The $\mathrm{H}$ areal density is obtained from the ERD signal taking into account the energy loss and straggling of $\mathrm{H}$ recoils in the $\mathrm{Al}$ stopper foil as well as geometric straggling ${ }^{21}$ due to the variation of the scattering angle across the detector area. The combined RBS and ERD analysis allows for a quantification of the element concentrations (in atom \%) with an uncertainty below 2 atom \%. The RBS spectrum of Pd-capped hydrogenated Y shows that the film contains no oxygen ( $\mathrm{O}$ detection limit 1 atom \%) except for a thin surface layer within the $\mathrm{C}$ substrate 
- probably a result of surface polishing. It is important to note here, that no other light elements, in particular $\mathrm{F}$, could be detected in the $\mathrm{MO}_{x} \mathrm{H}_{y}$ films discussed in this work. Together with the previously observed characteristic transmittance window (Figure 5) and lattice constants, ${ }^{14}$ this increases the confidence that our RE hydride samples are nearly ideal $\beta$ $\mathrm{MH}_{x}$ reference materials. Besides oxygen, fluorine is a common impurity in rare-earth metals - especially in $\mathrm{Y}^{22}$ In the past, we observed high concentrations of $\mathrm{O}$ (up to 7 atom \%) and $\mathrm{F}$ (up to 13 atom \%) in many commercial Y metal sputter targets of nominal $99.9 \%$ purity. Such high F concentrations complicate the chemical analysis and obscure subsequent interpretation of charge balance and electronic properties. Hence, we use highpurity Y targets supplied by Stanford Advanced Materials (United States) to avoid these problems.

The RBS and ERD simulations shown in Figure 1 confirm that the $\mathrm{MO}_{x} \mathrm{H}_{y}$ film composition is homogeneous throughout the depth of the films. We have observed chemical gradients in a few samples prepared at deposition pressures far above the critical values of $p^{*}=0.3 \mathrm{~Pa}(\mathrm{Sc}), 0.5 \mathrm{~Pa}(\mathrm{Y})$, and $0.7 \mathrm{~Pa}$ (Gd). ${ }^{14}$ However, the interpretation of the compositionproperty relationships of such graded (and likely porous) films is rather ambiguous. Therefore, we have excluded these samples from further analysis.

Figure 2 shows the results of the ion beam chemical composition analysis of our $(\mathrm{Sc}, \mathrm{Y}, \mathrm{Gd}) \mathrm{O}_{x} \mathrm{H}_{y}$ thin films in a generalized ternary $\mathrm{M}-\mathrm{O}-\mathrm{H}$ composition-phase diagram. This construction is based on the similar properties of the

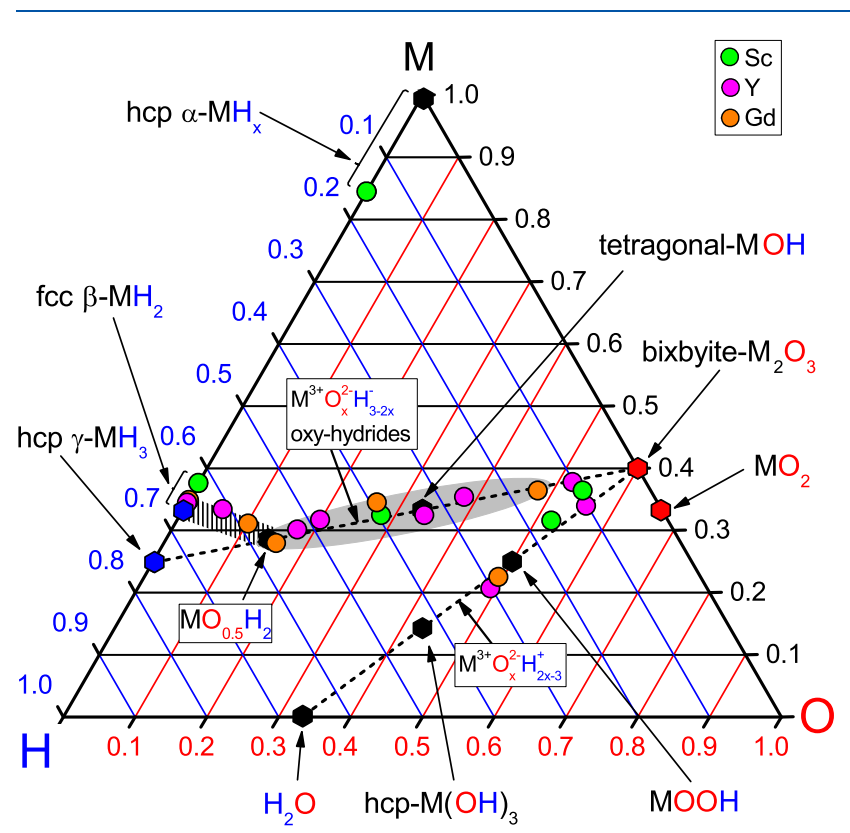

Figure 2. Ternary $\mathrm{M}-\mathrm{O}-\mathrm{H}$ chemical composition and phase diagram where $\mathrm{M}=\mathrm{Sc}, \mathrm{Y}, \mathrm{La}, \mathrm{Sm}-\mathrm{Lu}$. Thick dashed lines indicate chemical compositions with the same charge state of cations $\left(\mathrm{M}^{2+}, \mathrm{M}^{3+}, \mathrm{H}^{+}\right)$ and anions $\left(\mathrm{O}^{2-}, \mathrm{H}^{-}\right)$. Hexagons mark the (ideal) stoichiometric compounds that have been reported earlier: (i) binary compounds: $\mathrm{MH}_{2}$ dihydride and $\mathrm{MH}_{3}$ trihydride in blue as well as $\mathrm{M}_{2} \mathrm{O}_{3}$ sesquioxides ${ }^{23,24}$ and $\mathrm{MO}_{2}$ in red; (ii) ternary compounds: $\mathrm{MOH}$ oxyhydrides, ${ }^{5-7} \mathrm{MOOH}$ oxy-hydroxide, $\mathrm{M}(\mathrm{OH})_{3}$ hydroxide, ${ }^{25}$ and the hypothetical $\mathrm{MO}_{0.5} \mathrm{H}_{2}$ in black. Colored circles show the chemical compositions of $\mathrm{MO}_{x} \mathrm{H}_{y}$ thin films obtained from ion beam analysis. Note that the diameter of the data points corresponds to a composition uncertainty of approximately \pm 1 atom $\%$. The region of photochromic materials is highlighted in gray. binary RE metal oxides and hydrides. At ambient conditions, the $\mathrm{RE}$ metals form stable $\mathrm{M}_{2} \mathrm{O}_{3}$ sesquioxides (except $\mathrm{CeO}_{2}$ ) with a cubic bixbyite $(\mathrm{I} a \overline{3})$ structure (except $\mathrm{La}, \mathrm{Pr}$, and $\mathrm{Nd}){ }^{23}$ All RE metals readily dissolve hydrogen, forming a random interstitial $\alpha-\mathrm{MH}_{x}$ alloy where $\mathrm{H}$ occupies a fraction of the tetrahedral sites in the hexagonal close-packed (hcp) RE lattice. Upon hydrogenation, a phase transition to the metallic fcc $(F m \overline{3} m) \beta-\mathrm{MH}_{2}$ occurs for all REs. Further hydrogenation leads to a metal to insulator transition near $\mathrm{H} / \mathrm{M}=3$. For most REs, this is accompanied by a structural phase transition to hcp $\gamma-\mathrm{MH}_{3}$ (except Sc, La, Pr, Nd). Moreover, the REs form hcp $\mathrm{M}(\mathrm{OH})_{3}$ hydroxides $^{25}$ and various $\mathrm{MOOH}$ oxy-hydroxide phases.

Our results show that the chemical composition of the Sc, Y, and Gd-based thin films follow the same general trends in the $\mathrm{M}-\mathrm{O}-\mathrm{H}$ diagram. Two material groups can be clearly distinguished by considering the formal valencies and demanding charge neutrality (indicated by dashed lines). The RE oxyhydrides with a composition range of $\mathrm{M}^{3+} \mathrm{O}_{x}^{2-} \mathrm{H}_{3-2 x}^{-}$ $(0.5 \leq x \leq 1.5)$ are found on the line connecting $\mathrm{MH}_{3}$ and $\mathrm{M}_{2} \mathrm{O}_{3}$. In particular, at $x=1$ this includes the stoichiometric LnOH bulk compounds mentioned earlier. At $x=0.5$, the data points deviate from the $\mathrm{M}^{3+} \mathrm{O}_{x}^{2-} \mathrm{H}_{3-2 x}^{-}$line toward $\mathrm{MH}_{2}$ (hatched area). This is consistent with our previous work showing that as-deposited films sputtered in $\mathrm{Ar} / \mathrm{H}_{2}$ are metallic dihydrides that oxidize in air to form transparent photochromic films. ${ }^{14} \mathrm{We}$ obtain gray opaque films with compositions between $\mathrm{MH}_{2}$ and $\mathrm{MO}_{0.5} \mathrm{H}_{2}$ by sputtering at pressures near $p^{*}$. Their composition range in the ternary $\mathrm{M}-$ $\mathrm{O}-\mathrm{H}$ diagram suggests that initially the air-oxidation proceeds via insertion of oxide ions into the $\mathrm{MH}_{2}$ lattice accompanied by oxidation of $\mathrm{M}^{2+}$ cations to $\mathrm{M}^{3+}$. The opaque character of these films is characteristic for intermixed metallic and dielectric phases indicating nucleation of semiconducting $\mathrm{MO}_{0.5} \mathrm{H}_{2}$ in $\beta$ $\mathrm{MH}_{2}$. Note that $\mathrm{MO}_{0.5} \mathrm{H}_{2} \quad(x=0.5)$ marks the (ideal) composition where the conduction band is fully depleted of electrons (all cations are in the $\mathrm{M}^{3+}$ state) resulting in a metalinsulator transition that is observed in terms of the appearance of an optical band gap. Increasing the pressure above $p^{*}$ or adding small amounts of $\mathrm{O}_{2}$ during deposition leads to the formation of transparent semiconducting oxyhydrides with compositions between $\mathrm{MO}_{0.5} \mathrm{H}_{2}$ and $\mathrm{M}_{2} \mathrm{O}_{3}$. In contrast, the $\mathrm{RE}$ hydroxides with the composition range $\mathrm{M}^{3+} \mathrm{O}_{x}^{2-} \mathrm{H}_{2 x-3}^{+}(1.5 \leq x$ $\leq 3)$ are located on the line connecting $\mathrm{M}_{2} \mathrm{O}_{3}$ and $\mathrm{M}(\mathrm{OH})_{3}$. These transparent films were obtained by further increasing the $\mathrm{O}_{2}$ fraction in the $\mathrm{Ar} / \mathrm{H}_{2} / \mathrm{O}_{2}$ mixture during reactive sputtering.

$\mathrm{XRD}$ analysis confirms that all RE oxyhydride films in Figure 2 have fcc unit cell symmetry, where the lattice constant is expanded by $(1.0-2.8) \%$ relative to the dihydride because of oxygen incorporation (see XRD analysis in the Supporting Information). Moreover, the lattice constants of sputtered dihydrides, oxyhydrides, and oxides show a systematic variation with the RE ion radius according to the lanthanide contraction effect. ${ }^{14}$ By combining the structural similarities of the known stoichiometric compounds and the chemical composition results, we propose a generalized simplified structure model for the RE oxyhydrides as shown in Figure 3. It is based on the fcc $(F m \overline{3} m)$ structure where the 4 lattice sites are occupied by the RE cations and the compounds differ only in the average anion occupation of the 8 tetrahedral and 4 octahedral interstices per unit cell. In this framework, the $\mathrm{M}_{2} \mathrm{O}_{3}$ oxides can be described by a random $6 / 8$ occupation of 


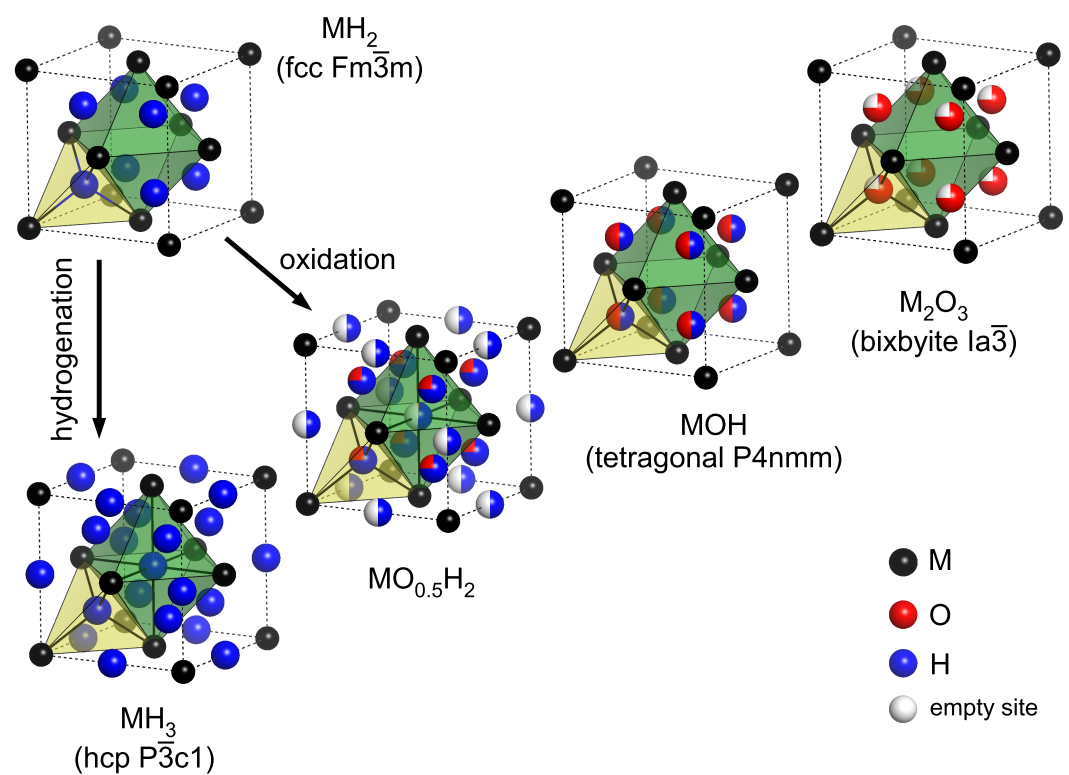

Figure 3. Generalized crystal structure evolution of rare-earth oxyhydrides with different $\mathrm{H}^{-} / \mathrm{M}$ and $\mathrm{O}^{2-} / \mathrm{M}$ ratios based on the fcc-fluorite $(F m \overline{3} m)$ structure motif. Anion sublattice disorder is visualized by multicolored spheres in terms of partial occupancy of tetrahedral (yellow polygon) and octahedral (green polygon) sites. The corresponding anion-ordered crystal structures of fcc- $\mathrm{MH}_{2}, \mathrm{hcp}-\mathrm{MH}_{3}$, tetragonal $\mathrm{MOH}^{5,6}$ and bixbyite- $\mathrm{M}_{2} \mathrm{O}_{3}{ }^{24}$ are given in parentheses. The arrows indicate metal-insulator transitions.

tetrahedral sites by $\mathrm{O}^{2-}$, where anion-ordering would lead to a distortion of the fcc symmetry resulting in the bixbyite- $\mathrm{M}_{2} \mathrm{O}_{3}$ structure. The idealized structure of stoichiometric $\mathrm{MH}_{2}$ is an fcc $(F m \overline{3} m)$ lattice where all 8 tetrahedral sites are occupied by $\mathrm{H}^{-}$ions. Additional filling of the 4 octahedral sites by $\mathrm{H}^{-}$leads to the idealized $\mathrm{MH}_{3}$ structure. While the trihydrides of $\mathrm{La}, \mathrm{Ce}$, $\mathrm{Pr}$, and $\mathrm{Nd}$ remain in the fcc structure up to $\mathrm{H} / \mathrm{M} \approx 3$, the most common hcp structure of the $\mathrm{RE} \gamma-\mathrm{MH}_{3}$ can be interpreted as a distorted fcc lattice where the cubic (111) axis is parallel to the hcp $c$-axis. The structure of the stochiometric $\mathrm{LnOH}$ powder materials was previously described as a fcc $(F m \overline{3} m)$ where the tetrahedral sites are randomly occupied by $\mathrm{O}^{2-}$ and $\mathrm{H}^{-}$with a $1: 1$ ratio. $^{7}$ The corresponding anionordered structure is tetragonal $(\mathrm{P} 4 / \mathrm{nmm}){ }^{5}$

The resulting generalized picture of anion-disordered fcc symmetry as shown in Figure 3 illustrates that in the $\mathrm{M}^{3+} \mathrm{O}_{x}^{2-} \mathrm{H}_{3-2 x}^{-}$oxyhydrides the cation-to-anion ratio changes from 1:1.5 in $\mathrm{M}_{2} \mathrm{O}_{3}$ to $1: 3$ in $\mathrm{MH}_{3}$. This implies that the $\mathrm{MOH}$ composition $(x=1)$ marks a transition point regarding the occupation of tetrahedral and octahedral interstices. For $x>1$, the octahedral sites are empty and additional structural tetrahedral vacancies are forming with increasing oxygen content up to a maximum amount of $25 \%$ in the $\mathrm{M}_{2} \mathrm{O}_{3}$ structure. In the case of $x<1$, all tetrahedral sites are occupied and the octahedral sites are successively filled with hydride ions with increasing hydrogen content.

We observe photochromism of the oxyhydrides over a wide composition range for both $x<1$ and $x>1$, as shown by the highlighted gray area in Figure 2. However, the exact composition boundaries for photochromic $\mathrm{MO}_{x} \mathrm{H}_{3-2 x}$ remain unclear. Regarding the lower boundary, we did not obtain any oxyhydrides with $x<0.5$ by either postoxidation of metallic $\beta$ $\mathrm{MH}_{2}$ films or direct growth using oxygen-poor $\mathrm{Ar} / \mathrm{H}_{2} / \mathrm{O}_{2}$ gas mixtures. This suggests that, in contrast to what was reported by You et al., ${ }^{12} \mathrm{H} / \mathrm{M}$ ratios above 2 in RE oxyhydride films cannot be achieved by reactive MS. This is because the typical $\mathrm{H}_{2}$ partial pressures of a few $10 \mathrm{mPa}$ during sputtering are far below the equilibrium pressure of the $\mathrm{MH}_{2} \rightarrow \mathrm{MH}_{3}$ phase transition $\left(p_{\mathrm{H}_{2}} \approx 0.1 \mathrm{~Pa}\right)^{26,27}$ and the addition of $\mathrm{O}_{2}$ to the process gas favors further dehydrogenation. Therefore, we prepared a $\gamma-\mathrm{YH}_{2.7+\delta}(x=0)$ thin film by hydrogenation of a Pd-capped sputtered Y metal film at $p_{\mathrm{H}_{2}}=3.2 \mathrm{kPa}$ in a vacuum cell mounted into our in situ spectrometer. This trihydride did not show photochromism at RT, whereas air-oxidized RE dihydride films with $x \approx 0.5$ are photochromic. Hence, this value is marked as the $\mathrm{O}$-poor boundary for photochromic $\mathrm{RE}$ oxyhydrides in Figure 2.

In order to discuss the O-rich boundary for photochromism, the effect of the anion ratio on optical properties has to be considered. Transmittance spectra of $\mathrm{YO}_{x} \mathrm{H}_{y}$ films are presented in Figure 4. The dense $\mathrm{YH}_{x}$ film prepared at $p=0.3 \mathrm{~Pa}$ (i.e., far below the critical deposition pressure for $\mathrm{Y}$ ) shows a transmittance window centered around $700 \mathrm{~nm}$ characteristic of metallic $\beta-\mathrm{YH}_{1.9+\delta}$ dihydride, which is caused by a combination of weak interband and free-electron absorption. ${ }^{28}$ The RE oxyhydride and hydroxide films are transparent semiconductors. The optical band gap of $\mathrm{Y}$ oxyhydride increases continuously with increasing $\mathrm{O}^{2-}$ content from $(2.5 \pm 0.1) \mathrm{eV}$ at $x \approx 0.7$ up to $(4.9 \pm 0.2) \mathrm{eV}$ at $x \approx 1.4$ (Figure 5). An extrapolation of this nonlinear trend (dashed line) leads to good agreement with the band gaps of $\mathrm{Y}_{2} \mathrm{O}_{3}$ (5.6 $\mathrm{eV})$ and $\mathrm{YH}_{3}(2.6 \mathrm{eV})$, which are determined by the $\mathrm{O} 2 \mathrm{p} \rightarrow$ $\mathrm{Y} 3 \mathrm{~d}$ and $\mathrm{H} 1 \mathrm{~s} \rightarrow \mathrm{Y} 3 \mathrm{~d}$ interband transition, respectively. ${ }^{29}$ Therefore, the upper valence band of the RE oxyhydrides is likely formed by a mixture of occupied $\mathrm{H} 1 \mathrm{~s}$ and $\mathrm{O} 2 \mathrm{p}$ states where the valence band maximum (VBM) shifts to lower energies with increasing $\mathrm{O}^{2-}$ concentration because of the higher electronegativity of oxygen $\left(\chi_{\mathrm{O}}=3.44\right)$ compared to hydrogen $\left(\chi_{\mathrm{H}}=2.20\right)$. The resulting band gap widening of the $\mathrm{Y}$ oxyhydrides does not depend linearly on the anion composition. This "band gap bowing" effect also occurs in many other semiconducting multianion compounds such as oxysulfides, ${ }^{30,31}$ oxynitrides, ${ }^{32}$ and III-V materials. ${ }^{33}$ Its origin can be traced back to the mismatch in atomic orbital energy 


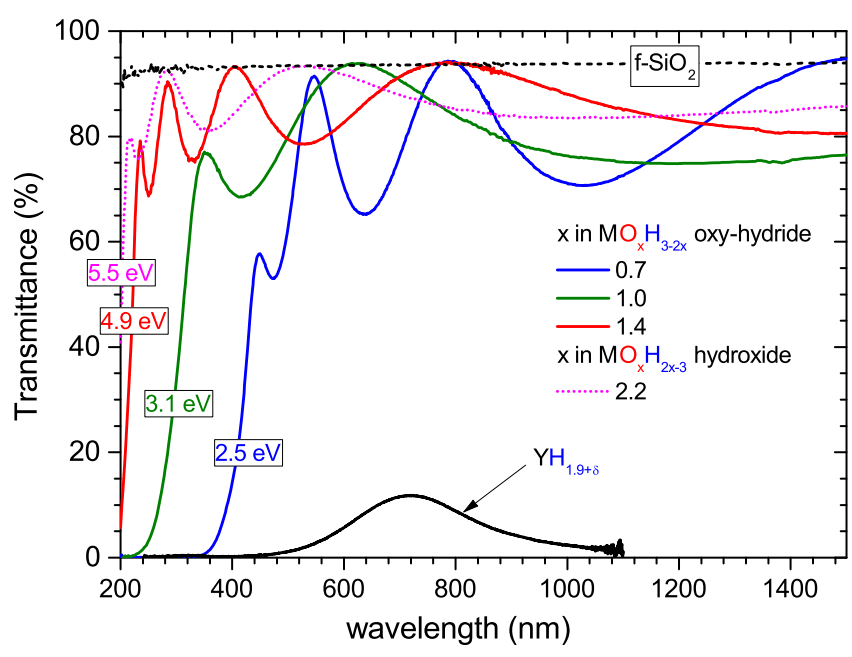

Figure 4. Transmittance spectra of Y-based ternary $\mathrm{M}-\mathrm{O}-\mathrm{H}$ films corresponding to Figure 2 with different compositions illustrating the metal-insulator transition from the dihydride $\mathrm{YH}_{1.9+\delta}$ to the oxyhydride $\mathrm{MO}_{x} \mathrm{H}_{3-2 x}$ phase followed by band gap widening with increasing $\mathrm{O}^{2-} / \mathrm{H}^{-}$ratio. The transmittance of a hydroxide-like film with a large $\mathrm{H}^{+}$concentration of $\sim 30$ atom \% is shown for comparison. The optical band gap values as obtained from Tauc plots are given. The black dashed line is the transmittance of the bare fused silica substrate.

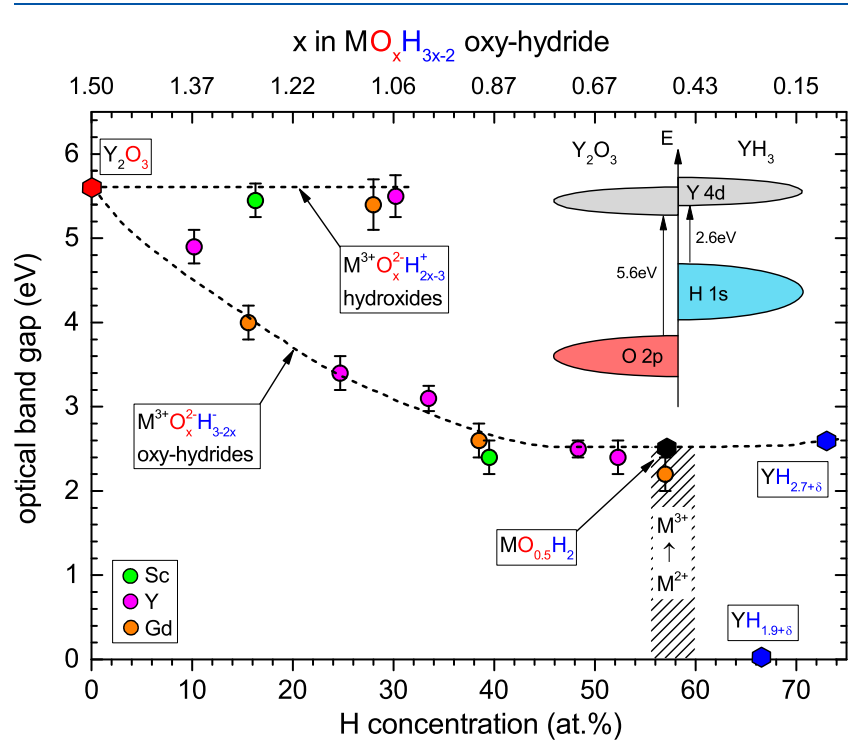

Figure 5. Dependence of the $\mathrm{MO}_{x} \mathrm{H}_{y}$ optical band gap on the hydrogen concentration where $\mathrm{M}=\mathrm{Sc}, \mathrm{Y}, \mathrm{Gd}$ (colored circles). Reported band gap values of the binary compounds $\mathrm{Y}_{2} \mathrm{O}_{3},{ }^{24} \mathrm{YH}_{2.7+\delta}$, and metallic $\mathrm{YH}_{1.9+\delta}$ are shown as colored hexagons. The metalinsulator transition upon oxidation of $\mathrm{M}^{2+}$ to $\mathrm{M}^{3+}$ with the hypothetical end point at $\mathrm{MO}_{0.5} \mathrm{H}_{2}$ is represented by the hatched region. Dashed lines are a guide to the eye and correspond to the charge-neutrality lines describing $\mathrm{M}^{3+}$ oxyhydrides and hydroxides in Figure 2. The fundamental electronic transitions of the binary end members of the $\mathrm{Y}$ oxyhydrides are illustrated.

and (an)ion size, which leads to coupling of electronic states affecting the relative positions of the VBM and the conduction band minimum (CBM) in random alloys. ${ }^{34}$ It seems plausible that these established principles also apply to the electronic structure of the oxyhydrides. However, comprehensive studies on this topic are still lacking.
Figure 5 shows that the band gaps of the Sc- and Gd-based oxyhydrides follow the same trend as $\mathrm{YO}_{x} \mathrm{H}_{3-2 x}$, which is reasonable considering the similarity in band gaps of the oxides: $\mathrm{Sc}_{2} \mathrm{O}_{3}(\sim 5.8 \mathrm{eV})^{35}$ and $\mathrm{Gd}_{2} \mathrm{O}_{3}(5.4 \mathrm{eV})^{36}$ as well as the trihydride $\mathrm{GdH}_{3}(2.5 \mathrm{eV}){ }^{37}$ Slightly lower $E_{\mathrm{g}}$ values $(-0.3 \mathrm{eV})$ for $\mathrm{M}=\mathrm{Sc}$, Gd are observed in oxyhydrides with low oxygen content $(x \approx 0.5)$. This is in agreement with our work ${ }^{14}$ on $\mathrm{MO}_{x} \mathrm{H}_{y}$ with $\mathrm{M}=\mathrm{Y}, \mathrm{Gd}, \mathrm{Dy}, \mathrm{Er}$ and indicates that the effect of different $\mathrm{RE}$ cations on $E_{\mathrm{g}}$ is relatively weak compared to anion-alloying. Moreover, all RE hydroxide thin films have large optical band gaps $\left(E_{\mathrm{g}} \approx 5.5 \mathrm{eV}\right)$ which are independent of the anion composition and similar in value to the sesquioxides, suggesting that the unoccupied $\mathrm{H}$ 1s orbitals do not interfere with the states at the VBM and CBM. Given the chemical similarity of the RE elements, we suppose that the anioncomposition dependence of the optical band gap of most lanthanide oxyhydrides closely resembles the trend shown in Figure 5. Notable exceptions are expected for $\mathrm{M}=\mathrm{Ce}, \mathrm{Pr}, \mathrm{Eu}$, $\mathrm{Tb}$ where the $\mathrm{M} 4 \mathrm{f}$ orbitals are located within the $\mathrm{O} 2 \mathrm{p} \rightarrow$ M 5d forbidden gap, resulting in a reduction of the $\mathrm{M}_{2} \mathrm{O}_{3}$ optical band gaps. ${ }^{36,38}$

Our ongoing photodarkening experiments with wavelengthdependent excitation indicate that photon energies larger than $E_{\mathrm{g}}$ are required to trigger photochromism in RE oxyhydrides. Using UV excitation by $\mathrm{Hg}$ vapor lamps with $\lambda=254 \mathrm{~nm}$, we observe weak photochromism in $\mathrm{YO}_{x} \mathrm{H}_{3-2 x}$ oxyhydrides with band gaps up to $4.2 \mathrm{eV}$. According to Figure 5 this corresponds to $x=1.3\left(c_{\mathrm{H}} \approx 15\right.$ atom \%) which is marked as the oxygenrich boundary for photochromism in Figure 2.

In conclusion, we have established a ternary $\mathrm{RE}-\mathrm{O}-\mathrm{H}$ composition-phase diagram demonstrating that (i) the previously reported photochromic Y-based thin films ${ }^{10,14}$ are $\mathrm{O}^{2-} / \mathrm{H}^{-}$multianion compounds which are members of the $\mathrm{REO}_{x} \mathrm{H}_{3-2 x}$ oxyhydrides material class including $\mathrm{Sc}$ and (most of) the lanthanides and that (ii) an anion-disordered fcc lattice model can be used to describe the crystal structure of the RE oxyhydrides linking the known $\mathrm{REH}_{3}, \mathrm{RE}_{2} \mathrm{O}_{3}$, and $\mathrm{LnOH}^{5-7}$ phases. These oxyhydride films are photochromic over nearly their entire composition range of $0.5 \leq x \leq 1.5$, which implies that the presence of both oxide and hydride ions is crucial for the photochromic effect at ambient conditions. We notice a general trend toward decreased photochromic contrast and faster bleaching kinetics with increasing $\mathrm{O}^{2-} / \mathrm{H}^{-}$ratio-in agreement with the report of Moldarev et al. ${ }^{15}$ On the basis of our results, we expect that the stoichiometric bulk $\mathrm{LnOH}$ compounds $(x=1)$ should be photochromic as well. Moreover, the RE oxyhydride optical band gap can be adjusted over a wide range by controlling the $\mathrm{O}^{2-} / \mathrm{H}^{-}$anion ratio in order to adapt the photochromic response for applications such as energy-saving smart windows and adaptive eyewear. Further systematic investigation of the electronic structure and defect formation is required to clarify the origin and physical limitations of the photochromic effect in the $\mathrm{REO}_{x} \mathrm{H}_{y}$ materials.

\section{ASSOCIATED CONTENT}

\section{S Supporting Information}

The Supporting Information is available free of charge on the ACS Publications website at DOI: 10.1021/acs.jpclett.9b00088.

Structural characterization by XRD, SEM, and AFM and further experimental details (PDF) 


\section{AUTHOR INFORMATION}

\section{Corresponding Author}

*E-mail: s.cornelius@tudelft.nl. Phone: +31(0)1527-87391.

ORCID $\odot$

Steffen Cornelius: 0000-0002-0358-7287

Giorgio Colombi: 0000-0001-6424-7684

Bernard Dam: 0000-0002-8584-7336

\section{Notes}

The authors declare no competing financial interest.

\section{ACKNOWLEDGMENTS}

The authors thank Dr. Nathan Nesbitt for facilitating access to the SEM and performing SEM measurements, Bart Boshuizen for programming the in-situ spectrometer control software, and Marcel Bus for performing AFM measurements. This work is part of the Open Technology research program with project number 13282, which is (partly) financed by The Netherlands Organisation for Scientific Research (NWO).

\section{REFERENCES}

(1) Kageyama, H.; Hayashi, K.; Maeda, K.; Attfield, J. P.; Hiroi, Z.; Rondinelli, J. M.; Poeppelmeier, K. R. Expanding frontiers in materials chemistry and physics with multiple anions. Nat. Commun. 2018, 9, 722.

(2) Hayward, M. A.; Cussen, E. J.; Claridge, J. B.; Bieringer, M.; Rosseinsky, M. J.; Kiely, C. J.; Blundell, S. J.; Marshall, I. M.; Pratt, F. L. The hydride anion in an extended transition metal oxide array: $\mathrm{LaSrCoO}_{3} \mathrm{H}_{07}$. Science 2002, 295, 1882-1884.

(3) Kobayashi, Y.; Hernandez, O.; Tassel, C.; Kageyama, H. New chemistry of transition metal oxyhydrides. Sci. Technol. Adv. Mater. 2017, 18, 905-918.

(4) Kobayashi, G.; Hinuma, Y.; Matsuoka, S.; Watanabe, A.; Iqbal, M.; Hirayama, M.; Yonemura, M.; Kamiyama, T.; Tanaka, I.; Kanno, R. Pure $\mathrm{H}^{-}$conduction in oxyhydrides. Science 2016, 351 (6729), 1314.

(5) Malaman, B.; Brice, J. F. Structural study of the hydride-oxide $\mathrm{LaOH}$ by X-ray diffraction and neutron-diffraction. J. Solid State Chem. 1984, 53, 44-54.

(6) Widerøe, M.; Fjellvag, H.; Norby, T.; Poulsen, F. W.; Berg, R. W. $\mathrm{NdOH}$, a novel oxyhydride. J. Solid State Chem. 2011, 184, 18901894.

(7) Zapp, N.; Kohlmann, H. The lanthanide hydride oxides $\mathrm{SmOH}$ and HoOH. Z. Naturforsch., B: J. Chem. Sci. 2018, 73, 535.

(8) Yamashita, H.; Broux, T.; Kobayashi, Y.; Takeiri, F.; Ubukata, H.; Zhu, T.; Hayward, M. A.; Fujii, K.; Yashima, M.; Shitara, K.; et al. Chemical pressure-induced anion order-disorder transition in LnHO enabled by hydride size flexibility. J. Am. Chem. Soc. 2018, 140, 11170.

(9) Ueda, J.; Matsuishi, S.; Tokunaga, T.; Tanabe, S. Preparation, electronic structure of gadolinium oxyhydride and low-energy $5 \mathrm{~d}$ excitation band for green luminescence of doped $\mathrm{Tb}^{3+}$ ions. J. Mater. Chem. C 2018, 6, 7541.

(10) Mongstad, T.; Platzer-Bjorkman, C.; Maehlen, J. P.; Mooij, L. P.; Pivak, Y.; Dam, B.; Marstein, E. S.; Hauback, B.; Karazhanov, S. Z. A new thin film photochromic material: oxygen-containing yttrium hydride. Sol. Energy Mater. Sol. Cells 2011, 95, 3596-3599.

(11) Mongstad, T.; Platzer-Bjorkman, C.; Karazhanov, S. Z.; Holt, A.; Maehlen, J. P.; Hauback, B. C. Transparent yttrium hydride thin films prepared by reactive sputtering. J. Alloys Compd. 2011, 509, S812-S816.

(12) You, C. C.; Moldarev, D.; Mongstad, T.; Primetzhofer, D.; Wolff, M.; Marstein, E. S.; Karazhanov, S. Z. Enhanced photochromic response in oxygen-containing yttrium hydride thin films transformed by an oxidation process. Sol. Energy Mater. Sol. Cells 2017, 166, 185189.

(13) Montero, J.; Martinsen, F. A.; Lelis, M.; Karazhanov, S. Z.; Hauback, B. C.; Marstein, E. S. Preparation of yttrium hydride-based photochromic films by reactive magnetron sputtering. Sol. Energy Mater. Sol. Cells 2018, 177, 106-109.

(14) Nafezarefi, F.; Schreuders, H.; Dam, B.; Cornelius, S. Photochromism of rare-earth metal-oxy-hydrides. Appl. Phys. Lett. 2017, 111, 103903.

(15) Moldarev, D.; Moro, M. V.; You, C. C.; Baba, E. M.; Karazhanov, S. Z.; Wolff, M.; Primetzhofer, D. Yttrium oxyhydrides for photochromic applications: Correlating composition and optical response. Phys. Rev. Mater. 2018, 2, 115203.

(16) Gremaud, R.; Slaman, M.; Schreuders, H.; Dam, B.; Griessen, $\mathrm{R}$. An optical method to determine the thermodynamics of hydrogen absorption and desorption in metals. Appl. Phys. Lett. 2007, 91, 231916.

(17) Remhof, A.; Kerssemakers, J. W. J.; van der Molen, S. J.; Kooij, E. S.; Griessen, R. Hysteresis in $\mathrm{YH}_{x}$ films observed with in-situ measurements. Phys. Rev. B: Condens. Matter Mater. Phys. 2002, 65, No. 054110.

(18) Manchester, F. D.; Pitre, J. M. The H-Sc system. J. Phase Equilib. 1997, 18, 194-205.

(19) Mayer, M. SIMNRA, a simulation program for the analysis of NRA, RBS and ERDA. AIP Conf. Proc. 1998, 475, 541-544 https:// home.mpcdf.mpg.de/ mam/. .

(20) Ziegler, J.F.; Ziegler, M.D.; Biersack, J.P. SRIM 2013; 2013; www.srim.org.

(21) Szilagyi, E. Energy spread in ion beam analysis. Nucl. Instrum. Methods Phys. Res., Sect. B 2000, 161-163, 37-47.

(22) Takenouchi, A.; Otomo, K. N.; Sakai, M.; Saito, Y.; Kirigane, T.; Kosaka, M.; Michimura, S.; Hasegawa, S.; Nakamura, O. Purification of commercial yttrium metal: Removal of fluorine. $J$. Cryst. Growth 2017, 468, 701-704.

(23) Zinkevich, M. Thermodynamics of rare earth sesquioxides. Prog. Mater. Sci. 2007, 52, 597-647.

(24) Adachi, G.; Imanaka, N. The binary rare earth oxides. Chem. Rev. 1998, 98, 1479-1514.

(25) Beall, G. W.; Milligan, W.; Wolcott, H. A. Structural trends in the lanthanide trihydroxides. J. Inorg. Nucl. Chem. 1977, 39, 65-70.

(26) Kooij, E. S.; van Gogh, A. T. M.; Griessen, R. In situ resistivity measurements and optical transmission and reflection spectroscopy of electrochemically loaded switchable $\mathrm{YH}_{x}$ films. J. Electrochem. Soc. 1999, 146 (8), 2990-2994.

(27) Huiberts, J. N.; Rector, J. H.; Wijngaarden, R. J.; Jetten, S.; de Groot, D.; Dam, B.; Koeman, N. J.; Griessen, R.; Hjörvarrson, B.; Olafsson, S.; et al. Synthesis of yttriumtrihydride films for ex-situ measurements. J. Alloys Compd. 1996, 239, 158-171.

(28) van Gogh, A. T. M.; Nagengast, D. G.; Kooij, E. S.; Koeman, N. J.; Rector, J. H.; Griessen, R.; Flipse, C. F. J.; Smeets, R. J. J. G. Structural, electrical, and optical properties of $\mathrm{La}_{1-z} \mathrm{Y}_{z} \mathrm{H}_{x}$ switchable mirrors. Phys. Rev. B: Condens. Matter Mater. Phys. 2001, 63, 195105.

(29) Miyake, T.; Aryasetiawan, F.; Kino, H.; Terakura, K. GW quasiparticle band structure of $\mathrm{YH}_{3}$. Phys. Rev. B: Condens. Matter Mater. Phys. 2000, 61, 16491-16496.

(30) Meyer, B. K.; Polity, A.; Farangis, B.; He, Y.; Hasselkamp, D.; Krämer, T.; Wang, C. Structural properties and bandgap bowing of $\mathrm{ZnO}_{1-x} \mathrm{~S}_{x}$ thin films deposited by reactive sputtering. Appl. Phys. Lett. 2004, 85, 4929.

(31) Persson, C.; Platzer-Björkman, C.; Malmström, J.; Törndahl, T.; Edoff, M. Strong valence-band offset bowing of $\mathrm{ZnO}_{1-x} \mathrm{~S}_{x}$ enhances p-type nitrogen doping of $\mathrm{ZnO}$-like alloys. Phys. Rev. Lett. 2006, 97, 146403.

(32) Xie, R.; Hintzen, H. T. Optical properties of (oxy)nitride materials: A Review. J. Am. Ceram. Soc. 2013, 96, 665-687.

(33) Vurgaftman, I.; Meyer, J. R.; Ram-Mohan, L. R. Band parameters for III-V compound semiconductors and their alloys. $J$. Appl. Phys. 2001, 89, 5815.

(34) Wei, S.; Zunger, A. Band offsets and optical bowings of chalcopyrites and Zn-based II-VI alloys. J. Appl. Phys. 1995, 78, 3846.

(35) Afanas'ev, V. V.; Shamuilia, S.; Badylevich, M.; Stesmans, A.; Edge, L. F.; Tian, W.; Schlom, D. G.; Lopes, J. M. J.; Roeckerath, M.; Schubert, J. Electronic structure of silicon interfaces with amorphous 
and epitaxial insulating oxides: $\mathrm{Sc}_{2} \mathrm{O}_{3}, \mathrm{Lu}_{2} \mathrm{O}_{3}, \mathrm{LaLuO}_{3}$. Microelectron. Eng. 2007, 84, 2278-2281.

(36) Prokofiev, A. V.; Shelykh, A. I.; Melekh, B. T. Periodicity in the band gap variation of $\operatorname{Ln}_{2} \mathrm{X}_{3}(\mathrm{X}=\mathrm{O}, \mathrm{S}, \mathrm{Se})$ in the lanthanide series. $J$. Alloys Compd. 1996, 242, 41-44.

(37) Lee, M. W.; Lin, C. H. Determination of the optical constants of the y-phase $\mathrm{GdH}_{3}$ thin films. J. Appl. Phys. 2000, 87, 7798.

(38) Gillen, R.; Clark, S. J.; Robertson, J. Nature of the electronic band gap in lanthanide oxides. Phys. Rev. B: Condens. Matter Mater. Phys. 2013, 87, 125116. 